\section{IMPACTOS DAS POLÍTICAS EDUCACIONAIS NO COTIDIANO DAS \\ ESCOLAS PÚBLICAS PLANO NACIONAL DE EDUCAÇÃO}

Luiz Antonio Miguel Ferreira ${ }^{1}$

Flávia Maria de Barros Nogueira ${ }^{2}$

\section{RESUMO}

Este artigo analisa a relação do Plano Nacional de Educação com a escola, em especial, os reflexos que produz como políticas públicas em seu cotidiano. Também analisa a questão de sua judicialidade e suas consequências. Aborda o papel do Ministério Público como protagonista de ações que busquem a concretização dos planos, com a fiscalização dos prazos previstos, das metas, das estratégias e dos direitos assegurados. Com a constatação da falha, a negociação articulada e/ou a indução para a efetivação de política pública específica deve ser o caminho a seguir. O trabalho enfatiza que a participação de todos redunda do modelo democrático assumido pelo País e previsto constitucionalmente. Entretanto, essa participação tem outro efeito: o princípio do pertencimento da coisa pública.

Palavras-chave: Políticas educacionais. Direito à Educação. Judicialização da Educação. Participação.

\section{ABSTRACT}

This article analyzes the relationship of the National Education Plan with the school, especially the reflexes that produces as public policies in their daily lives. It also examines the question of its judicialidade and its consequences. Addresses the role of the public prosecution as the protagonist of actions that seek to achieve the plans, with the supervision of deadlines, goals, strategies and guaranteed rights. With a finding of failure to articulate negotiation and / or induction to the execution of specific public policy should be the way forward. It emphasizes that the participation of all redounds to the democratic model assumed by the country and set out constitutionally. But this participation has another effect: the principle of public affairs belonging.

Keywords: Educational policies. Right to Education. Legalization of Education. Participation.

\section{INTRODUÇÃO}

Espera-se da escola pública que ela seja para todos e de qualidade. Para alcançar esses objetivos, ou seja, uma escola comum que efetivamente cumpra com os objetivos propostos na Constituição Federal (Art. 205 - visar ao pleno desenvolvimento da pessoa, seu preparo para o exercício da cidadania e sua qualificação para o trabalho), políticas públicas são lançadas, como

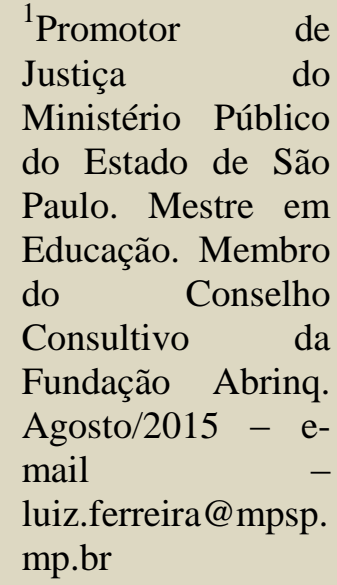

${ }^{2}$ Flávia Maria de Barros Nogueira. Diretora de Articulação com os Sistemas de Ensino(SASE),

Ministério da Educação (MEC) flavia.nogueira@m ec.gov.br 
forma de fazer com que o comando legal atinja o seu objetivo. Assim, numa análise preliminar, política pública na área educacional nada mais é do que a ponte que liga as determinações e objetivos legais com a realidade local. Por conseguinte, tais políticas têm uma ligação direta com a escola, visto que esta é o locus onde a realidade que necessita ser atingida se apresenta. Logo, toda escola sofre os reflexos advindos das políticas públicas educacionais, quer direta ou indiretamente.

O problema, como salienta Cury (2014),

é que o dever de Estado, a fim de satisfazer um direito do cidadão juridicamente protegido, convive com uma forma federativa de educação em suas atribuições e competências. Prossegue o autor: Resulta, então, termos em conjunto, tanto dimensões nacionais da educação nacional quanto dimensões federativas nos espaços subnacionais. (CURY, 2014, p. 31).

Devido a esse modelo, a Constituição Federal define a competência da União, dos Estados e Municípios e estabelece a necessidade da organização de seus sistemas de ensino em regime de colaboração (Art. 211). A Constituição prevê também o sistema nacional de educação, a ser articulado por um plano decenal (Art. 214, alterado pela Emenda Constitucional 59/2009). (BRASIL, 1988). O Plano Nacional de Educação (PNE) e, consequentemente, os planos estaduais, distrital,e municipais ultrapassam os planos plurianuais de governo. Exigem articulações institucionais e participação social para sua elaboração ou adequação, seu acompanhamento e avaliação. Para o cumprimento do dispositivo legal, foi publicado o Plano Nacional de Educação, aprovado pela lei $n^{\circ}$ 13.005/2014 (BRASIL, 2014a). Este plano nacional desdobrou-se nos planos estaduais e municipais (BRASIL, 2015b) e constituem, na atualidade, o desafio maior para implantação de uma educação de qualidade. Como política pública educacional, proporciona reflexos diretos no cotidiano escolar. A visão global desses reflexos é a proposta do presente artigo, que também assinala as consequências de sua não aplicação.

\section{POLÍtica PÚblica EdUCACIONAL - PLANO NACIONAL DE EDUCAÇÃO}

Antes de adentrar na análise do Plano Nacional de Educação, 
Impactos das políticas educacionais no cotidiano das escolas

públicas plano nacional de educação.

tornam-se prudentes breves considerações a respeito da elaboração das políticas públicas.

Segundo Rodrigues (2010), há ciclos ou processos de gestão na elaboração das políticas públicas. Assim, elas são concebidas como um “processo, composto por um conjunto de atividades (etapas ou estágios) que visam atender às demandas e aos interesses da sociedade", mas em consonância com a lei. A autora descreve os ciclos principais na elaboração das políticas públicas:

a) Preparação da decisão política - O governo decide enfrentar um determinado problema e buscar algum tipo de solução para uma situação que produz privação, necessidade ou não satisfação. O problema existe? O Governo deve se envolver nesse problema? De que maneira?

b) Agenda setting - A formação da agenda. Nesse momento, o problema torna-se uma questão política, isto é, adquire status de problema público e as decisões sobre esse problema resultarão, efetivamente, no desenho de políticas ou programas que deverão ser implementados.

c) Formulação - $\mathrm{Na}$ formulação das políticas públicas, a discussão passa a girar em torno do desenvolvimento de cursos de ações aceitáveis e pertinentes para lidar com um determinado problema público. A construção da solução para um determinado problema implica, em primeiro lugar, a realização de um diagnóstico. Para que o programa/político saia do papel, é preciso interpretar o ambiente para planejar/organizar as ações, decidir sobre quais os benefícios/serviços que se pretende implementar, e de onde serão extraídos os recursos para sua implementação.

d) Implementação - Em resumo, significa a aplicação da política pela máquina burocrática do Governo. Trata-se do momento de preparação para colocar as ações do Governo em prática.

e) Monitoramento - Como as agências administrativas afetam e conferem conteúdo às políticas adotadas, há necessidade de se realizar uma avaliação pontual das ações de Governo referentes ao impacto da implementação.

f) Avaliação - Por fim, a atividade de avalição de resultados da política/programa concentra-se nos efeitos gerados (RODRIGUES, 2010, p. 47-48).

Resumindo todo esse trajeto, esclarece a citada autora que:

Políticas públicas resultam, portanto, da atividade política, 
envolvem mais de uma decisão política e requerem várias ações estratégicas destinadas a implementar objetivos desejados. Constituem um conjunto articulado de ações, decisões e incentivos que buscam alterar uma realidade em resposta a demandas e interesses envolvidos.

$\begin{array}{lr}{ }^{3} \text { O Fundo de } \\ \text { Manutenção } & \mathrm{e} \\ \text { Desenvolvimento } & \text { da } \\ \text { Educação Básica e de } & \text { de } \\ \text { Valorização rof do } & \text { da } \\ \text { Profissionais } & \text { da }\end{array}$

Políticas públicas são ações de Governo, portanto, são revestidas da autoridade soberana do poder público. Dispõem sobre "o que fazer" (ações), "aonde chegar" (metas ou objetivos relacionados ao estado de coisas que se pretende alterar) e "como fazer" (estratégias de ação) (RODRIGUES, 2010, p. 52-53).

$\mathrm{Na}$ esfera educacional, várias políticas públicas foram lançadas por todos os setores do governo federal para se alcançar os objetivos propostos pela Constituição Federal. A título de exemplo, entre outras políticas, podem ser citadas as seguintes:

Educação (FUNDEB)

foi criado pela

Emenda

Constitucional $\quad \mathrm{n}^{\circ}$

53/2006 e

regulamentado pela

Lei $n^{\circ} 11.494 / 2007$ e

pelo Decreto $\mathrm{n}^{\circ}$

6.253/2007, em substituição

FUNDEF, que

a) Fundo de Manutenção e Desenvolvimento do Ensino Fundamental e de Valorização do Magistério- (FUNDEF);

vigorou de 1998 a 2006.

b) Plano de Desenvolvimento da Escola (PDE);

c) Programa de Dinheiro Direto na Escola (PDDE);

d) Programa Bolsa Família (PBF);

e) Programa Nacional de Alimentação Escolar (PNAE);

f) Programa Nacional do Livro Didático (PNLD);

g) Programa Nacional de Transporte Escolar (PNATE);

h) Exame Nacional do Ensino Médio (ENEM);

i) Sistema de Seleção Unificada (SISU);

j) Programa Universidade para Todos (PROUNI);

k) Programa Nacional de Reestruturação e Aquisição de Equipamentos para a Rede Escolar Pública de Educação Infantil (PROINFÂNCIA).

O Plano Nacional de Educação é a política pública mais atual e tem como objetivo a melhoria da educação. Está amparado na Constituição Federal e visa efetivar os deveres do Estado em relação à Educação. Assim, ao analisar os Artigos 208 e 214 da Constituição Federal, pode-se extrair a razão política dos Planos de Educação. Diz a lei:

Art. 208. O dever do Estado com a educação será efetivado mediante a garantia de: 
Impactos das políticas educacionais no cotidiano das escolas

públicas plano nacional de educação.

I - educação básica obrigatória e gratuita dos 4 (quatro) aos 17 (dezessete) anos de idade, assegurada inclusive sua oferta gratuita para todos os que a ela não tiveram acesso na idade própria;

II - progressiva universalização do ensino médio gratuito;

III - atendimento educacional especializado aos portadores de deficiência, preferencialmente na rede regular de ensino;

IV - educação infantil, em creche e pré-escola, às crianças até 5 (cinco) anos de idade;

$\mathrm{V}$ - acesso aos níveis mais elevados do ensino, da pesquisa e da criação artística, segundo a capacidade de cada um;

VI - oferta de ensino noturno regular, adequado às condições do educando;

VII - atendimento ao educando, em todas as etapas da educação básica, por meio de programas suplementares de material didáticoescolar, transporte, alimentação e assistência à saúde.

Art. 214. A lei estabelecerá o plano nacional de educação, de duração decenal, com o objetivo de articular o sistema nacional de educação em regime de colaboração e definir diretrizes, objetivos, metas e estratégias de implementação para assegurar a manutenção e desenvolvimento do ensino em seus diversos níveis, etapas e modalidades por meio de ações integradas dos poderes públicos das diferentes esferas federativas que conduzam a:

I - erradicação do analfabetismo;

II - universalização do atendimento escolar;

III - melhoria da qualidade do ensino;

IV - formação para o trabalho;

V - promoção humanística, científica e tecnológica do País;

VI - estabelecimento de meta de aplicação de recursos públicos em educação como proporção do produto interno bruto. (BRASIL, 1988, grifo nosso).

Podem-se definir os planos de educação como documentos (políticas públicas), "com força de lei, que estabelecem metas para que a garantia do direito à educação de qualidade avance em um município, estado ou país, no período de dez anos.” (POR UMA PARTICIPAÇÃO..., 2015).

Os planos devem contemplar a realidade nacional, estadual e municipal, razão pela qual se mostra de extrema relevância o diagnóstico realizado. A seguir, metas, estratégias e diretrizes precisam ser definidas de modo a contemplar a melhoria da educação em face da realidade apresentada. Bordignon (2014) esclarece:

DIRETRIZES: Indicam a direção a seguir na caminhada, balizada pelas políticas e por princípios indicando o rumo a seguir e o futuro desejado. Estabelecem as definições normativas das políticas. 
METAS: Constituem objetivos quantificados e datados. Representam o compromisso dos governos e da sociedade, orientando a ação dos agentes públicos e o controle social.

ESTRATÉGIAS: Devem constituir programas definidores das ações do governo para alcançar as metas. (BORDIGNON, 2014, p. 31-32).

Por fim, há de se ter uma visão sistêmica dos Planos (PNE, PEE e PME), de forma que se apresentem de maneira articulada e com capilaridade, em razão do sistema federativo e do regime de colaboração estabelecido em lei.

Como política pública, os Planos de Educação apresentam características comuns com outros planos, e específicas, em razão da matéria tratada. Podemse enumerar as seguintes características ou premissas (BRASIL, 2015a) listadas abaixo:

a) PME precisa estar alinhado ao PNE e ao PEE. Considerando que os planos municipais de educação poderão ser limitados ou potencializados pelos planos estaduais, é recomendável que todos os segmentos da sociedade e das três esferas de governo se envolvam na construção dos PEEs da mesma forma que se envolveram na construção do PNE e façam o mesmo com relação ao PME no seu respectivo município. O PEE precisa refletir uma pactuação entre o governo estadual e os governos municipais em cada estado, pois as metas estaduais devem ser refletidas em uma combinação de metas municipais em cada unidade da federação. A soma das metas estaduais, por sua vez, deve ser suficiente para o alcance das metas nacionais. Por esse motivo, o necessário encadeamento da construção das metas entre o PNE, PEEs e PMEs;

b) PME deve ser do município, e não apenas da rede ou do sistema municipal. O Plano Municipal de Educação é de todos que moram no município; portanto, todas as necessidades educacionais do cidadão devem estar presentes no plano, o que vai muito além das possibilidades de oferta educacional direta da prefeitura. Também não se trata do plano de uma 
Impactos das políticas educacionais no cotidiano das escolas públicas plano nacional de educação.

administração da prefeitura ou da secretaria municipal de educação, pois atravessa mandatos de vários prefeitos e dirigentes municipais de educação. O trabalho pressupõe o envolvimento das três esferas de gestão (federal, estadual e municipal) e de representações dos diversos segmentos da sociedade, mas não deixa de conferir peso e importância ao papel dos dirigentes municipais. Para assegurar qualidade e dar peso político ao plano, é desejável que o prefeito e seus secretários assumam papel de destaque, como importantes lideranças na construção das decisões que vincularão o projeto educacional com o projeto de desenvolvimento local;

c) Intersetorialidade é uma premissa estratégica para dar sentido ao Plano, considerando que o projeto de educação de um município não é tarefa apenas do órgão gestor da rede de ensino, mas do conjunto de instituições dos governos, com a participação ativa da sociedade. O PME terá a responsabilidade de traduzir e conciliar os desejos, as necessidades e as capacidades educacionais do município para a oferta da educação básica (em todas as suas etapas e modalidades) e também de ensino superior. Precisa levar em consideração a trajetória histórica, as características socioculturais e ambientais, a vocação e a perspectiva de futuro do município;

d) É preciso conhecer bem o cenário atual para projetar o futuro com base em decisões coerentes e pactuadas. A efetividade do PME depende em grande parte do real dimensionamento das demandas educacionais, das fragilidades, dos desafios e das potencialidades do município. Essas demandas e necessidades precisam ser comparadas com a capacidade atual e futura de investimentos da prefeitura e possíveis aportes do governo estadual, da união e de outras fontes;

e) O plano deve se articular aos demais instrumentos de planejamento. Os insumos necessários para a execução dos planos de educação terão de constar nos orçamentos da união e dos estados para que apoiem técnica e financeiramente os municípios ao longo da década. $\mathrm{Na}$ prefeitura, 
instrumentos de planejamento terão de se vincular ao plano decenal de educação: Plano Plurianual (PPA), Lei de Diretrizes Orçamentárias (LDO), Lei Orçamentária Anual (LOA), Plano de Ações Articuladas (PAR), entre outros;

f) Por fim, uma premissa indispensável de trabalho é o fato de que o plano de educação tem de ter legitimidade para ter sucesso. Planos construídos em gabinetes ou por consultores alheios à realidade municipal ou do estado tendem ao fracasso, mas um plano submetido ao amplo debate incorpora a riqueza das diferentes visões e vivências que a sociedade tem sobre a realidade que deseja alterar. Somente um plano municipal de educação legítimo pode contar com o apoio de todos para monitorar seus resultados e impulsionar a sua concretização, através da mobilização da sociedade ao longo dos seus dez anos de vigência.

Também podem ser citadas as seguintes características:

a) PLANO QUE TRANSCENDA UM MANDATO - descontinuidade das políticas que orientam a gestão educacional. PLANOS DE ESTADO;

b) DURADOURO E FACTÍVEL;

c) PLANOS QUE ORIENTEM A TOMADA DE DECISÃO POLÍTICA NA CONDUÇÃO DAS AÇÕES ESTABELECIDAS;

d) FUNDA-SE NA GOVERNABILIDADE: a capacidade do governo de implementar programas econômicos e sociais por meio de uma gestão eficiente, eficaz e que responda às necessidades de expansão da economia, garantindo estabilidade institucional, segurança jurídica e direitos individuais e coletivos (MARTINS, PIMENTA; NOVAES, 2014, p. 278).

e) DEVE RESPEITAR A LEGISLAÇÃO E LEIS ORÇAMENTÁRIAS MAS COM PLANOS PARA O FUTURO;

f) TRANSPARÊNCIA - Informação que vá além da disponibilização de dados e avance no tratamento de tais informações, tornando-as compreensíveis e amigáveis para a população. 
Impactos das políticas educacionais no cotidiano das escolas públicas plano nacional de educação.

O comando geral parte do Plano Nacional de Educação e proporciona o efeito cascata para atingir os planos estaduais e os municipais. Assim, não há como negar que o deliberado na esfera nacional repercute diretamente na municipal. Mas esta repercussão não é automática e muito menos factível se não ocorrer a efetiva participação de todos os seguimentos na elaboração dos planos municipais e com uma visão sistêmica.

A participação de todos redunda do modelo democrático assumido pelo País e previsto constitucionalmente. Mas esta participação tem outro efeito, o princípio do pertencimento da coisa pública, ou seja, "as pessoas tendem a se comprometer com o que lhes pertence, o que lhes diz respeito". Quando se tem um plano elaborado com a efetiva participação dos professores, educadores, pais, funcionários, vereadores, do executivo, enfim, de toda a sociedade, a possibilidade de não se tornar um plano fictício ou dissociado da realidade local é muito menor, pois cobranças advirão da sua implementação, inclusive em esferas extra educacionais, com a participação do Ministério Público e Judiciário.

Mas, para ser efetiva, essa participação deve seguir o modelo abaixo, ou seja, o interessado tem que estar informado do plano e sensibilizado de sua real necessidade e potencialidade. Capacitação e mobilização são as outras esferas que levam a este pertencimento, ou seja, que faz com que a política pública seja eficaz e eficiente.

Essa participação é algo recente na história dos planos de educação, 
já que, em sua maioria, "nos últimos cinquenta anos, com exceção do PNE aprovado pelo Congresso Nacional em 2001, foram formulados pelo Executivo" (VIEIRA, 2014, p. 63). Em outras palavras, a intervenção legislativa é recente, assim como a participação da comunidade em geral. No entanto, a lógica atual quanto à elaboração dos planos é da concreta participação de todos, sendo uma etapa indispensável às audiências públicas realizadas para discussão e aprovação.

Nesse sentido, o próprio Plano Nacional de Educação, instituído pela Lei ${ }^{\circ} 13.005 / 2014$, estabelece:

Art. $8^{\circ}, \S 2^{\circ}$ - Os processos de elaboração e adequação dos planos de educação dos Estados, do Distrito Federal e dos Municípios, de que trata o caput deste artigo, serão realizados com AMPLA

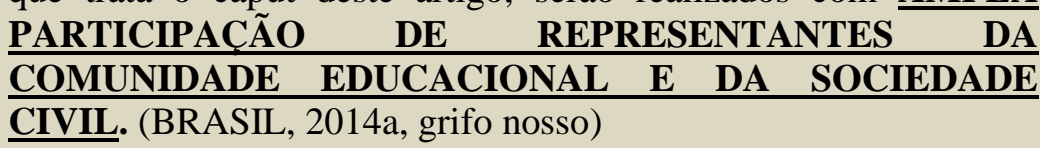

Além dessa participação, devem os planos ser elaborados com uma visão sistêmica do contexto educacional. Como afirma Bordignon (2014):

Visão sistêmica: um plano de educação, seja nacional, estadual ou municipal, além da contextualização em sua dimensão própria, deve ser referenciado, conectado na dimensão da nacionalidade, de todo nacional, ou seja, os diferentes planos não podem ser concebidos como sistemas fechados, mas abertos e articulados, trocando energias entre si, estabelecendo a sinergia no todo. É o espírito do princípio constitucional do regime de colaboração, que implica a definição de responsabilidades comuns, próprias e compartilhadas dos sistemas de ensino no todo nacional (BORDIGNON, 2014, p. 35).

Em representação: 
Impactos das políticas educacionais no cotidiano das escolas

públicas plano nacional de educação.

O Plano Nacional de Educação, com suas vinte (20) metas, repercute diretamente na política pública educacional do município, afetando as ações na escola, até porque, o plano nacional acaba por direcionar as metas dos planos municipais. Diante deste contexto, basta uma simples análise em algumas metas para se constatar tal assertiva.

\section{IMPACTOS NO COTIDIANO ESCOLAR}

As políticas públicas se propõem a provocar alterações "no interior da escola, em especial, nos seus princípios e, por decorrência, na forma de organização e desenvolvimento do trabalho escolar, portanto, interferindo diretamente nas práticas dos professores e em sua cultura" (DELGADO, 2011, p. 3). Prossegue a autora:

[...] a construção de uma nova cultura escolar, com outras práticas, normas e concepções, não depende apenas de mudanças legais, mas, sobretudo, da criação de condições efetivas para tal, o que incide em alterações das condições de trabalho oferecidas ao professor, estrutura da escola e preparo técnico e pedagógico aos docentes (DELGADO, 2011, p. 3).

A lei por si só não altera a realidade. É obvio que todas as metas do Plano Nacional de Educação, como política pública que é, voltada para a melhoria da educação, repercute no cotidiano das escolas, sejam elas públicas, municipais, estaduais ou particulares. No entanto, trata-se de um propósito 
legal que somente repercutirá em ambiente propício a alterações, com interferência na cultura escolar.

Analisando de maneira global as metas do Plano Nacional de Educação, segundo os documentos oficiais, pode-se afirmar que há um primeiro grupo de metas estruturantes para a garantia do direito à educação básica com qualidade, que dizem respeito ao acesso, à universalização da alfabetização e à ampliação da escolaridade e das oportunidades educacionais (Metas 1, 2, 3, 5, 6, 7, 9, 10 e 11). Investir fortemente na educação infantil, conferindo centralidade no atendimento das crianças de 0 a 5 anos, é a tarefa e o grande desafio do município. Para isso, é essencial o levantamento detalhado da demanda por creche e pré-escola, de modo a materializar o planejamento da expansão, inclusive com os mecanismos de busca ativa de crianças em âmbito municipal, projetando o apoio do estado e da União para a expansão da rede física (no que se refere ao financiamento para reestruturação e aparelhagem da rede) e para a formação inicial e continuada dos profissionais da educação. É importante uma maior articulação dos municípios e estados com as instituições formadoras no ambiente dos Fóruns Estaduais Permanentes de Apoio à Formação Docente para o desenvolvimento de programas de formação que tenham como foco a profissionalização em serviço. Outro desafio nacional é assegurar acesso pleno de crianças e jovens de 6 a 17 anos aos ensinos fundamental e médio, inclusive com ampliação da oferta de educação profissional. Esse trabalho exige colaboração entre redes estaduais e municipais e acompanhamento da trajetória educacional de cada estudante. $\mathrm{O}$ estado precisa fortalecer seu papel de coordenação no território, fazendo busca ativa e viabilizando o planejamento de matrículas de forma integrada aos municípios, bem como incorporando instrumentos de monitoramento e avaliação contínua em colaboração com os municípios e com a União. Há, ainda, a necessidade de que os estados e os municípios projetem a ampliação e a reestruturação de suas escolas na perspectiva da educação integral, e, nesse contexto, é estratégico considerar a articulação da escola com os diferentes equipamentos públicos, espaços educativos, culturais e esportivos, revitalizando os projetos pedagógicos das escolas nessa direção.

Um segundo grupo de metas diz respeito especificamente à 
redução das desigualdades e à valorização da diversidade, caminhos imprescindíveis para a equidade (Metas 4 e 8). A política pública deve fortalecer sistemas educacionais inclusivos em todas as etapas, viabilizando acesso pleno à educação básica obrigatória e gratuita. A juventude (jovens e jovens adultos, conforme o Estatuto da Juventude) do campo, das regiões mais pobres e a negra devem ganhar centralidade nas medidas voltadas à elevação da escolaridade, de forma a equalizar os anos de estudo em relação aos demais recortes populacionais. Os estados e os municípios devem organizar-se e entender esses desafios como compromissos com a equidade, contando com o apoio federal para viabilizar o atendimento das pessoas com deficiências, transtornos globais do desenvolvimento e altas habilidades ou superdotação, em salas de recursos multifuncionais, classes, escolas ou serviços especializados, públicos ou conveniados.

\section{O terceiro bloco de metas trata da valorização dos profissionais}

da educação, considerada estratégica para que as metas anteriores sejam atingidas (Metas 15 a 18). Um quadro de profissionais da educação motivados e comprometidos com os estudantes de uma escola é indispensável para o sucesso de uma política educacional que busque a qualidade referenciada na Constituição Brasileira. Planos de carreira, salários atrativos, condições de trabalho adequadas, processos de formação inicial e continuada e formas criteriosas de seleção são requisitos para a definição de uma equipe de profissionais com o perfil necessário à melhoria da qualidade da educação básica pública. Portanto, estabelecer política de valorização dos profissionais da educação em cada rede ou sistema de ensino é fundamental para que a política educacional se fortaleça. Quanto mais sustentáveis forem as carreiras e quanto mais integradas forem as decisões relativas à formação, mais ampliadas serão as perspectivas da equidade na oferta educacional. Para assegurar que todos os professores da educação básica tenham formação específica de nível superior, obtida em curso de licenciatura na área de conhecimento em que atuam, o planejamento deve se dar a partir da análise das reais necessidades de cada escola, consideradas na gestão de cada rede ou sistema, com contínuo aperfeiçoamento das estratégias didático- pedagógicas. Para a elaboração de planos estratégicos de formação, devem ser implantados os Fóruns Estaduais 
Permanentes de Apoio à Formação Docente, previstos na Política Nacional de Formação de Profissionais do Magistério da Educação Básica (Decreto $\mathrm{n}^{\circ}$ 6.755/2009) (BRASIL, 2009). Em vários estados, os fóruns já se encontram fortalecidos e institucionalmente apoiados. À União cabe um forte papel de financiamento e a coordenação nacional.

Um quarto grupo de metas (Metas 12, 13 e 14) refere-se ao ensino superior, que, em geral, é de responsabilidade dos governos federal e estaduais. Seus sistemas abrigam a maior parte das instituições que atuam nesse nível educacional, mas isso não significa descompromisso dos municípios. É no ensino superior que tanto os professores da educação básica quanto os demais profissionais que atuarão no município são formados, contribuindo para a geração de renda e desenvolvimento socioeconômico local. Por essas razões, a União, os estados, o Distrito Federal e os municípios devem participar da elaboração das metas sobre o ensino superior nos planos municipais e estaduais, vinculadas ao PNE.

Para que o País atinja as metas, há a questão do financiamento. A previsão constitucional de vinculação de um percentual do PIB para execução dos planos de educação representa um enorme avanço, mas o desafio de vincular os recursos a um padrão nacional de qualidade ainda está presente. $\mathrm{Na}$ agenda instituinte do Sistema Nacional de Educação, o financiamento, acompanhado da definição de normas de cooperação, de padrões nacionais de qualidade e de uma descentralização qualificada, isto é, de repartição de competências acompanhadas das condições necessárias para sua efetivação, levará à ampliação da capacidade de atendimento, e todos os brasileiros terão seu direito assegurado em qualquer ponto do território nacional. Também estão presentes outros grandes desafios, como o fortalecimento da gestão democrática, com leis específicas que a normatizem em cada rede ou sistema de ensino. Esses são elementos imprescindíveis do Sistema Nacional de Educação a ser instituído, conforme preveem, especialmente, as metas 19 e 20 do $\mathrm{PNE}^{4}$.

É óbvio que todas essas metas guardam uma relação direta com o cotidiano da escola. Mas, numa breve análise de algumas delas, pode-se

${ }^{4}$ Conhecendo as 20 metas do PNE (BRASIL, 2014b). 
Impactos das políticas educacionais no cotidiano das escolas

públicas plano nacional de educação.

constatar de maneira mais específica tal assertiva. Vejamos:

META 1: Universalizar, até 2016, a EDUCAÇÃO INFANTIL na pré-escola para as crianças de 4 (quatro) a 5 (cinco) anos de idade e ampliar a oferta de educação infantil em CRECHES de forma a atender, no mínimo, $50 \%$ (cinquenta por cento) das crianças de até 3 (três) anos até o final da vigência deste PNE. (BRASIL, 2014b).

Centrando na questão das creches, é inegável a sua interferência. Como atender toda esta demanda é a primeira indagação. Colocar as crianças nas creches sem a garantia de um padrão mínimo de qualidade não é o caminho a ser construído. A garantia do número máximo de crianças por professor é fundamental, assim como todos os demais quesitos relacionados à qualidade, como merenda, transporte, formação profissional, recursos materiais, didáticos e humanos, etc. Logo, para se atingir tal meta, torna-se imprescindível uma ação articulada e planejada para não transformar creches em depósito de crianças para que os pais possam trabalhar. Vale registrar que a questão da qualidade da educação infantil encontra-se entre as estratégias do PNE (a de $\left.n^{\circ} 1.6\right)$ e em vários documentos oficiais, como:

a) Parâmetros Nacionais de Qualidade para as Instituições de Educação Infantil (Vol. n² 2 - Brasília: MEC, 2006);

b) Diretrizes Curriculares Nacionais para a Educação Infantil (RESOLUÇÃO CNE/CEB n 01, de 07/04/99), e a revisão do Parecer $n^{\circ}$ 20/09, Resolução CNE $n^{\circ}$ 5, de 17/02/2009, e Resolução $n^{\circ}$ 4, de 13/07/2010, que define as Diretrizes Curriculares Nacionais Gerais para a Educação Básica. Fonte?

Pode-se afirmar o mesmo em relação à universalização da pré-escola. Universalizar a matrícula é bem diferente de universalizar a pré-escola. A universalização da matrícula está próxima de se concretizar. Contudo, o número de crianças e adolescentes evadidos revela uma face obscura dessa universalização. Ademais, se entre as estratégias se encontra a questão da busca ativa (estratégia 1.15 do PNE), como ela será realizada pela escola? Quem será o responsável? Que tipo de ação realizar?

Todas essas indagações refletem alguns problemas que deverão ser 
enfrentados no cotidiano educacional. Outra meta:

META 4: Universalizar, para a população de 4 (quatro) a 17 (dezessete) anos com deficiência, transtornos globais do desenvolvimento e altas habilidades ou superdotação, o acesso à educação básica e ao atendimento educacional especializado, preferencialmente na rede regular de ensino, com a garantia de SISTEMA EDUCACIONAL INCLUSIVO, de salas de recursos multifuncionais, classes, escolas ou serviços especializados, públicos ou conveniados. Fonte?

O PNE institui o que se denomina SISTEMA EDUCACIONAL INCLUSIVO, que é bem diferente de educação inclusiva. Num sistema, todos estão envolvidos. A inclusão não é mais responsabilidade somente do professor. Isso implica um redesenho da escola quando se analisa a questão da pessoa com deficiência, visto que um sistema deve abarcar:

a) formação do professor;

b) adequação do ambiente escolar;

c) capacitação dos funcionários;

d) escola adequada a cada aluno, observando suas necessidades pessoais e pedagógicas;

e) comunidade escolar preparada para receber os alunos com deficiência;

f) participação da família no processo educativo do aluno com deficiência;

g) adequação curricular;

h) número de alunos na sala de aula.

Esse sistema acabou por ser incorporado na Lei $\mathrm{n}^{\circ} 13.146$, de 06 de julho de 2015, que Instituiu a Lei Brasileira de Inclusão da Pessoa com Deficiência (Estatuto da Pessoa com Deficiência), tratando em capítulo específico do direito à educação (Artigos 27 a 30). Destaca-se, desta legislação, os deveres impostos ao poder público (Art. 28), que são:

Art. 28. Incumbe ao poder público assegurar, criar, desenvolver, implementar, incentivar, acompanhar e avaliar:

I - sistema educacional inclusivo em todos os níveis e modalidades, bem como o aprendizado ao longo de toda a vida; II - aprimoramento dos sistemas educacionais, visando a garantir condições de acesso, permanência, participação e aprendizagem, 
por meio da oferta de serviços e de recursos de acessibilidade que eliminem as barreiras e promovam a inclusão plena;

III - projeto pedagógico que institucionalize o atendimento educacional especializado, assim como os demais serviços e adaptações razoáveis, para atender às características dos estudantes com deficiência e garantir o seu pleno acesso ao currículo em condições de igualdade, promovendo a conquista e o exercício de sua autonomia;

IV - oferta de educação bilíngue, em Libras como primeira língua e na modalidade escrita da língua portuguesa como segunda língua, em escolas e classes bilíngues e em escolas inclusivas; $\mathrm{V}$ - adoção de medidas individualizadas e coletivas em ambientes que maximizem o desenvolvimento acadêmico e social dos estudantes com deficiência, favorecendo o acesso, a permanência, a participação e a aprendizagem em instituições de ensino;

VI - pesquisas voltadas para o desenvolvimento de novos métodos e técnicas pedagógicas, de materiais didáticos, de equipamentos e de recursos de tecnologia assistiva;

VII - planejamento de estudo de caso, de elaboração de plano de atendimento educacional especializado, de organização de recursos e serviços de acessibilidade e de disponibilização e usabilidade pedagógica de recursos de tecnologia assistiva;

VIII - participação dos estudantes com deficiência e de suas famílias nas diversas instâncias de atuação da comunidade escolar; IX - adoção de medidas de apoio que favoreçam o desenvolvimento dos aspectos linguísticos, culturais, vocacionais e profissionais, levando-se em conta o talento, a criatividade, as habilidades e os interesses do estudante com deficiência;

$\mathrm{X}$ - adoção de práticas pedagógicas inclusivas pelos programas de formação inicial e continuada de professores e oferta de formação continuada para o atendimento educacional especializado;

XI - formação e disponibilização de professores para o atendimento educacional especializado, de tradutores e intérpretes da Libras, de guias intérpretes e de profissionais de apoio;

XII - oferta de ensino da Libras, do Sistema Braille e de uso de recursos de tecnologia assistiva, de forma a ampliar habilidades funcionais dos estudantes, promovendo sua autonomia e participação;

XIII - acesso à educação superior e à educação profissional e tecnológica em igualdade de oportunidades e condições com as demais pessoas;

XIV - inclusão em conteúdos curriculares, em cursos de nível superior e de educação profissional técnica e tecnológica, de temas relacionados à pessoa com deficiência nos respectivos campos de conhecimento;

XV - acesso da pessoa com deficiência, em igualdade de condições, a jogos e a atividades recreativas, esportivas e de lazer, no sistema escolar;

XVI - acessibilidade para todos os estudantes, trabalhadores da educação e demais integrantes da comunidade escolar às edificações, aos ambientes e às atividades concernentes a todas as modalidades, etapas e níveis de ensino;

XVII - oferta de profissionais de apoio escolar; 
XVIII - articulação intersetorial na implementação de políticas públicas. (BRASIL, 2015c).

Destaca-se, neste artigo, a questão da oferta de PROFISSIONAIS DE APOIO ESCOLAR (Art. 28, XVII). A própria lei tratou de definir o que se entende por tal profissional no Artigo $3^{\circ}$, XIII, estabelecendo:

Art. $3^{\circ}$ - Para fins de aplicação desta Lei, consideram-se:

XIII - profissional de apoio escolar: pessoa que exerce atividades de alimentação, higiene e locomoção do estudante com deficiência e atua em todas as atividades escolares nas quais se fizer necessária, em todos os níveis e modalidades de ensino, em instituições públicas e privadas, excluídas as técnicas ou os procedimentos identificados com profissões legalmente estabelecidas; (BRASIL, 2015c).

Verifica-se que essa lei, referendando o PNE, repercutirá diretamente nas escolas que deverão se amoldar à nova realidade educacional para a pessoa com deficiência. Isso dependerá das ações do poder executivo, mas também das próprias unidades educacionais e dos pais e responsáveis que devem provocar a efetividade da lei.

"META 7: Fomentar a qualidade da educação básica em todas as etapas e modalidades, com melhoria do fluxo escolar e da aprendizagem de modo a atingir as seguintes médias nacionais para o IDEB.” (BRASIL, 2015c).

Sabe-se que os indicadores de qualidade, como o IDEB, é um, entre outros elementos, que compõem uma escola de qualidade. A melhoria no IDEB passa necessariamente pela ação do professor e, em especial, de sua formação (inicial e continuada). A política estadual ou municipal deve levar em consideração essa situação, para que se possa buscar os índices fixados. Não há dúvidas de que uma educação comprometida com a qualidade terá impactos no cotidiano escolar, atuando diretamente na sala de aula. Por outro lado, tal meta se articula com a questão da valorização profissional (meta 17), devendo ser analisada em conjunto.

Enfim, as metas previstas no Plano Nacional de Educação têm ou pelo menos pretendem ter suas raízes fincadas na escola pública, até porque não se faz educação sem as escolas, sem os professores. Daí porque há necessidade de a escola se apoderar de tal instrumental, realizando aquilo que é 
Impactos das políticas educacionais no cotidiano das escolas públicas plano nacional de educação.

de sua competência e cobrando dos gestores a sua efetiva implementação. Esse é o plano ideal.

No entanto, é sabido que não é pelo fato de o plano ter sido aprovado por lei que a realidade social mudará. A lei somente tem reflexos na sociedade quando é apropriada por todos. Por outro lado, o fato de se ter um plano de educação, como política pública, ainda provoca alguns questionamentos, como:

a) Há articulação entre os planos: nacional, estadual e municipal?

b) Ocorreu a efetiva participação de todos na sua elaboração, para justificar a sua apropriação?

c) O fato de se ter um plano como política pública significa que a educação melhorará?

Por outro lado, a própria lei que instituiu o Plano Nacional de Educação (Lei n. 13.005/14) estabeleceu no artigo $8^{\circ}$ a necessária articulação das políticas públicas. Diz a lei:

Art. $8^{\circ}-\S 1^{\circ}$ Os entes federados estabelecerão nos respectivos planos de educação estratégias que:

I - assegurem a ARTICULAÇÃO DAS POLÍTICAS EDUCACIONAIS COM AS DEMAIS POLÍTICAS SOCIAIS, particularmente as culturais; (BRASIL, 2014a).

A mudança educacional efetivamente ocorrerá quando as políticas públicas, e em especial os Planos Nacional, Estadual e Municipal, deixarem de ser peça de ficção ou carta de boas intenções para se tornarem realidade. Ademais, a execução desses planos passa pela questão orçamentária, de forma que o comprometimento do gestor deve ir além, garantindo verbas necessárias para a execução das metas e aplicação das estratégias. Paralelamente, a instituição do Sistema Nacional de Educação, para dar cumprimento ao Artigo 13 do PNE, deverá definir padrões nacionais para a oferta educacional, com respeito às diversidades e às diferenças. Deverá fixar normas de cooperação federativa claras para o exercício das competências comuns, com regras de financiamento adequadas à garantia dos padrões estabelecidos e às 
competências definidas, com sistemas de ensino organizados de forma a dar concretude ao instituto jurídico do Regime de Colaboração (BRASIL, 2015c). Tais movimentos de reorganização da educação nacional darão real concretude aos planos de educação, permitindo que estes cumpram a sua função constitucional: articular os sistemas de educação.

\section{JUDICIALIZAÇÃO DOS PLANOS - PAPEL DO MINISTÉRIO PÚBLICO}

Políticas públicas são constituídas de

todos os atos legislativos e administrativos necessários à satisfação espontânea dos direitos fundamentais sociais. Estabelecido o direito fundamental social, os Poderes Legislativo e Executivo, no âmbito de suas competências constitucionais, têm o dever de promover a sua irradiação formal e material. (CANELA JÚNIOR, 2011, p. 147).

Nesse sentido e como já afirmado, os planos de educação são documentos (políticas públicas), com força de lei, que estabelecem metas para que o direito à educação de qualidade avance no município, estado ou país, no período de dez anos. Como lei que é, estabelece direitos e também deveres que podem ser questionados judicialmente, pois não há como negar que o seu direcionamento se encontra no campo legal (Constituição e legislação infraconstitucional), com um poder vinculante ao administrador público. Também é nesse campo que se encontram os instrumentos jurídicos para a sua concretude e para a responsabilização pela omissão.

Sabe-se que esse recurso à Justiça tem se tornado frequente com uma verdadeira "Judicialização da educação". No entanto, a concretização das políticas públicas não se limita à esfera do Judiciário.

Como afirma Canela Júnior (2011):

O Poder Judiciário tem uma atribuição constitucional residual em matéria de políticas públicas. Isso significa que a jurisdição não pode intervir indistintamente nas políticas públicas desenvolvidas pelos demais poderes. Somente no caso de omissão ou de contrariedade com os núcleos constitucionais de irradiação é que o Poder Judiciário intervém nas políticas públicas (CANELA JÚNIOR, 2011, p. 148).

A concretização dos planos encontra no poder executivo o locus adequado 
Impactos das políticas educacionais no cotidiano das escolas

públicas plano nacional de educação.

para a sua realização. A Judicialização dos planos deve ser reservada de forma a ser exceção e não a regra. Isso, pelas seguintes razões:

a) a transferência de análise e concretização de uma política pública educacional nem sempre encontra no Judiciário a interpretação que melhor se adequa à realidade educacional (pode contemplar a realidade jurídica, mas não a educacional);

b) transfere-se uma construção coletiva e democrática para uma análise pessoal que pode se cercar de impressões descompromissadas com o cotidiano escolar;

c) em sua maioria, a análise das políticas reveste-se de caráter individual e não coletivo - o que proporciona desigualdades.

Basta citar como exemplo a questão das férias nas creches, a educação em período integral ou parcial e a idade mínima para a matrícula no ensino fundamental, para ter-se a exata compreensão do problema.

Apesar de as creches integrarem o sistema educacional, ainda são tratadas por grande parte do Judiciário como entidades assistencialistas que devem cuidar (e não educar) das crianças, a fim de que os pais possam trabalhar, de modo que funcionem ininterruptamente. No entanto:

O fechamento das creches nas férias é necessário uma vez que integram o sistema de ensino e devem ser guiadas pelas normas relativas à educação em geral. Como consta do Parecer 17/12, do $\mathrm{CNE}$, 'as férias constituem um momento imprescindível para a avaliação e o planejamento do trabalho pedagógico dos professores'.

Nas férias escolares, há necessidade de uma articulação das demais políticas públicas a fim de atender aquelas crianças que não têm condições familiares ou sociais de permanecer, em segurança e devido cuidado em casa. Excepcionalmente, enquanto não articulada a política pública para o atendimento desta demanda, o funcionamento das creches em regime de plantão no período de férias é uma alternativa para atendimento especial e excepcional de crianças em situação de risco pessoal ou social ou em situação de vulnerabilidade (FERREIRA; DIDONET, 2015).

A Justiça, muitas vezes, nega este direito elementar relacionado à educação a fim de que as creches funcionem como casas de acolhimento em

${ }^{5}$ Estratégia 1.17) estimular $\quad 0$ acesso à educação infantil em tempo integral, para todas as crianças de $\mathrm{O}$ (zero) a 5 (cinco) anos, conforme estabelecido nas Diretrizes Curriculares Nacionais para a Educação Infantil. 
período de recesso escolar.

Outro paradoxo do Judiciário nesta questão envolve o período escolar. O Plano Nacional de Educação contempla a questão do período integral e parcial das creches, prevendo de forma específica na estratégia $1.17^{5}$ da meta 01 o estímulo do acesso à educação infantil em tempo integral, o que não descarta o período parcial. Já na meta $06^{6}$ contempla a necessidade de se oferecer tempo integral na educação básica. Isso revela que não há impedimento ao oferecimento de creches em período parcial, pois esse direito deve conviver com outro direito, o da convivência familiar. Aliás, é o que também determina o artigo 34 da Lei de Diretrizes e Bases da Educação Nacional. No entanto, as decisões judiciais, ainda sob o manto assistencialista, sustentam a necessidade das creches em período integral. O problema é que a legislação e o Judiciário têm atuado, cada vez mais, em favor da não institucionalização das crianças (em entidades de acolhimento), mas admitem a institucionalização na educação. Não se distingue a escola em tempo integral com a educação integral. Aliás, merece destaque o Parecer 17/12 do CNE, que estabelece:

Quanto à jornada, de acordo com o que dispõe a Lei $\mathrm{n}^{\mathrm{o}}$ 11.494/2007, para todas as etapas da Educação Básica, as Diretrizes Curriculares Nacionais para a Educação Infantil estabelecem que a Educação Infantil deve ser ofertada às crianças em jornada parcial de, no mínimo, quatro horas diárias, ou em jornada integral, igual ou superior a sete horas diárias. É preciso levar em conta que a criança não deve permanecer em ambiente institucional e coletivo por jornada excessiva, sob o risco de não ter atendidas suas necessidades de recolhimento, intimidade e de convivência familiar. (BRASIL, 2012, grifo nosso).

Por fim, outro problema que está em evidência no Poder Judiciário diz respeito à idade mínima para se ingressar no ensino fundamental. Todo o regramento está consignado em lei e resoluções do Conselho Nacional ${ }^{7}$. A regra geral da idade mínima para o ingresso no ensino fundamental é que a criança deverá ter 6 (seis) anos completos até o dia 31 de março do ano em que ocorrer a matrícula. No entanto, a justiça admite uma variável do mês em que a criança completa os 06 anos de idade, de junho até dezembro. Não há uma uniformidade.
${ }^{6}$ Meta 6: oferecer educação em tempo integral em, no mínimo, $50 \%$ (cinquenta por cento) das escolas públicas, de forma a atender, pelo menos, $25 \%$ (vinte e cinco por cento) dos alunos da educação básica.
${ }^{7}$ CF, Art. 208, Resolução 04 e 06/2010 do CNE 
Impactos das políticas educacionais no cotidiano das escolas

públicas plano nacional de educação.

Portanto, é evidente que a Judicialização da educação, apesar de cada vez mais intensa, deve ser vista como uma exceção. Para que isso ocorra, há necessidade de que todos os envolvidos nas políticas públicas garantam a sua efetividade sem a necessidade de socorrer-se do Judiciário. Nesse particular, entram em ação: a escola, os professores, os conselhos de escola, os gestores, os sindicatos, a universidade, os pais e responsáveis, o Ministério Público, etc.

O Ministério Público deve assumir o papel de protagonista de ações que busquem a concretização dos planos, com a fiscalização dos prazos previstos, das metas, estratégias e dos direitos assegurados. Com a constatação da falha, a negociação articulada e/ou indução para a efetivação de política pública específica deve ser o caminho a seguir. O objetivo é o coletivo, ou seja, o direito à educação que garanta um atendimento democrático a toda a população. Nesse particular, destaca-se a importância da visão global do direito e não apenas o direito individual. A educação busca a igualização das pessoas, como direito social que é, assim, a visão do Ministério Público deve ser sempre o coletivo, para que esse direito seja garantido a todos, indistintamente.

Nesse sentido, esclarece Canela Júnior (2014):

Os direitos fundamentais sociais foram concebidos para garantir a igualdade substancial de todos os membros da sociedade. O objetivo da satisfação dos bens da vida protegidos pelos direitos fundamentais sociais é o oferecimento de oportunidades iguais de desenvolvimento a todos os integrantes da sociedade. Logo, esses bens da vida devem ser disponibilizados indistintamente, sem quaisquer privilégios particulares.

Se o que se objetiva com os direitos fundamentais sociais é a igualdade substancial (grifo nosso), não é possível que se conceba a existência de titulares exclusivos daqueles direitos, ou de determinados segmentos da sociedade que exclusivamente deles se beneficiem (CANELA JÚNIOR, 2014, p. 144, grifo nosso).

Essa situação traz reflexo direto na decisão judicial, pois se deve ter como objetivo o coletivo e não apenas o individual. No entanto, o Judiciário, muitas vezes, lida com o direito individual. Assim, compete ao Ministério Público, na eventualidade de judicializar a questão, levar ao Judiciário o direito pleiteado de forma coletiva e difusa, para que todos sejam beneficiados com eventual decisão judicial. Nesse sentido, mais uma vez merecem destaque os 
ensinamentos de Canela Júnior (2014):

[...] tal situação criou um sério paradoxo, pois, ao se conceber individualmente ao cidadão direito social, possibilita-se uma nítida distinção entre os que obtiveram a satisfação da pretensão e os que não a obtiveram. Nesse contexto, o Poder Judiciário, de forma reflexa, não reduz a desigualdade - mesmo fazendo atuar o ordenamento jurídico -, porquanto apenas uma parcela mínima dos cidadãos terá garantido o direito postulado (CANELA JÚNIOR, 2014, p. 144, grifo nosso).

Dessa forma, deve-se buscar uma igualdade que não seja apenas formal. Nesse sentido, o Ministério Público, através dos inquéritos civis, tem a possibilidade de garantir a igualização das pessoas de forma concreta, pois tais inquéritos se apresentam como instrumentos eficazes de concretização de políticas públicas. Trata-se de um mecanismo extrajudicial que permite a negociação através dos termos de ajustamento de conduta. A ação judicial para a implementação das políticas deve ser a última posição a ser tomada. Para tanto, cada vez mais se constata a necessidade de especialização dos promotores de justiça que atuam nessa área. Uma atuação regionalizada visando a uma solução que ultrapasse as barreiras geográficas de uma comarca, dado que o Plano Nacional e Estadual de Educação vale para todas as cidades. Os planos municipais levam a alguma especificidade, mas que deve estar em consonância com os demais planos (nacional e estadual)

\section{CONSIDERAÇÕES FINAIS}

A título de conclusão, vale destacar a evolução da agenda educacional e o patamar em que se encontra atualmente para bem direcionar as políticas públicas educacionais, em especial, os planos. Nesse sentido, afirma Barone:

A agenda educacional brasileira priorizou, ao longo dos anos 80, a expansão quantitativa da oferta, ampliando o acesso com a expansão da rede física, em detrimento do aspecto qualitativo. A baixa qualidade, então atribuída ao sistema escolar, foi associada à insuficiência de recursos para a educação, à centralização das decisões, à burocratização do sistema educacional, com a privatização e clientelização da política educacional, à exclusão da comunidade e profissionais dos processos decisórios e de gestão do sistema. Considerados obstruidores dos processos de modernização do setor educacional, esses aspectos orientaram as reformas que tinham como eixo a democratização da educação. 
Impactos das políticas educacionais no cotidiano das escolas

públicas plano nacional de educação.

Esses temas foram incorporados pela agenda educacional dos anos 90, quando a educação (re)assume uma posição de destaque nas perspectivas da cidadania e da formação para o trabalho, associada à perspectiva de retomada do crescimento do país. Diante da crescente incorporação de inovações tecnológicas, da demanda por novas qualificações e/ou competências, e em face das consequências de uma economia que vem se globalizando, há quase um consenso quando se trata de apontar que o sistema educacional brasileiro não vem respondendo às necessidades do novo perfil de qualificação da mão-de-obra. Nessa direção, um conjunto de ações orienta a busca da melhoria da qualidade do sistema educacional, tais como: iniciativas de caráter pedagógico voltadas para a diminuição da repetência e evasão no ensino fundamental, implantação de sistemas de avaliação, adequação dos conteúdos à população-alvo, redução do número de alunos por sala, investimentos no corpo docente (capacitação, melhoria salarial e melhores condições de trabalho, fornecimento de equipamentos básicos) (BARONE, 2015).

Hoje, a proposta é alcançar a qualidade educacional para que cumpra com o papel que lhe foi reservado constitucionalmente. Os objetivos claros dos Planos de Educação - ampliação do acesso e melhoria da qualidade do ensino em ambos os níveis, nas diferentes etapas e modalidades combinadas com valorização profissional, dão especial relevo à necessidade da instituição do Sistema Nacional de Educação. Os planos recém-elaborados vão sendo aperfeiçoados pelos mecanismos de monitoramento e avaliação. Quanto maior for a consonância entre as metas municipais, estaduais e nacionais, mais o PNE será capaz de cumprir seu papel articulador do Sistema Nacional de Educação. O desafio é grande, e o processo, que é coletivo, exigirá, fundamentalmente, disposição para compreender que todos fazem parte de uma unidade nacional para que o país avance em qualidade com equidade, com foco no direito de cada cidadão. Resta evidente que as políticas educacionais têm um impacto significativo junto à escola pública, pois é nela que se projetam as mudanças para se alcançar os objetivos e as metas traçados. Não é na judicialização que se conseguirá a melhora da educação. Esse é o último recurso a ser utilizado. Antes, deve haver o efetivo comprometimento de todos - Estado, Família e Sociedade (CF, artigos 205 e 227) - para a melhoria da educação e a implementação das políticas educacionais. 


\section{REFERÊNCIAS}

BARONE, Rosa Elisa M. Educação e políticas públicas: questões para o debate. [S. 1.]: SENAC, 2015. Disponível em: <http://www.senac.br/informativo/bts/263/boltec263a.htm> Acesso em: 30 ago. 2015

BORDIGNON, Genuíno. Caminhar da educação brasileira: muitos planos, pouco planejamento. In: SOUZA, Donaldo Bello de; MARTINS, Angela Maria (Org.). Planos de educação no Brasil: planejamento, políticas, práticas. São Paulo: Edições Loyola, 2014.

BRASIL. Constituição (1988). Constituição da República Federativa do Brasil, promulgada em 5 de outubro de 1988. 24. ed. São Paulo: Saraiva, 2000. (Coleção Saraiva de Legislação).

BRASIL. Conselho Nacional de Educação. Ministério da Educação. O plano municipal de educação: caderno de orientações. Brasília: CNE/ME, 2015a. Disponível em:

http://pne.mec.gov.br/images/pdf/pne_pme_caderno_de_orientacoes.pdf> Acesso em: 30 set. 2015.

BRASIL. Decreto n ${ }^{\circ} 6.755$, de 29 de janeiro de 2009. Institui a Política Nacional de Formação de Profissionais do Magistério da Educação Básica, disciplina a atuação da Coordenação de Aperfeiçoamento de Pessoal de Nível Superior -CAPES no fomento a programas de formação inicial e continuada, e dá outras providências. Diário Oficial da União, Brasília, 30 jan. 2009.

Disponível em: <http://www.planalto.gov.br/ccivil_03/_ato20072010/2009/decreto/d6755.htm> Acesso em: 21 set. 2015.

BRASIL. Estatuto da Criança e do Adolescente: promulgado em 13 de julho de 1990. 9. ed. São Paulo: Saraiva, 1999. (Coleção Saraiva de Legislação).

BRASIL. Lei de Diretrizes e Bases da Educação Nacional. Lei n 9.394, de 20 de dezembro de 1996. Brasília: LDB, 1996.

BRASIL. Lei $\mathrm{n}^{\circ} 13.005$, de 25 de junho de 2014. Aprova o Plano Nacional de Educação - PNE e dá outras providências. Diário Oficial da União, Brasília, 26 jun. 2014a. Disponível em: <http://legislacao.planalto.gov.br/legisla/legislacao.nsf/Viw_Identificacao/lei\% 2013. 005-2014?OpenDocument> Acesso em: 21 set. 2015.

BRASIL. Lei no 13.146, de 6 de julho de 2015.

Institui a Lei Brasileira de Inclusão da Pessoa com Deficiência (Estatuto da Pessoa com Deficiência).Diário Oficial da União, Brasília, 7 jul. 2015c. Disponível em: < http://www.planalto.gov.br/ccivil_03/_Ato20152018/2015/Lei/L13146.htm> Acesso em: 21 set. 2015.

BRASIL Ministério da Educação. Planejando a próxima década conhecendo 
Impactos das políticas educacionais no cotidiano das escolas

públicas plano nacional de educação.

as 20 Metas do Plano Nacional de Educação. Brasília: MEC/SASE, 2014 b. Disponível em: <

http://pne.mec.gov.br/images/pdf/pne_conhecendo_20_metas.pdf> Acesso em: 30 set. 2015.

BRASIL. Ministério da Educação. Planejando a próxima década: alinhando os planos de educação. Brasília: ME, 2015b. Disponível em: $<$ http://pne.mec.gov.br/alinhando-os-planos-de-educacao/situacao-dos-planosde-educacao> Acesso em: 30 set. 2015.

BRASIL. Ministério da Educação. Secretaria de Articulação com os Sistemas de Ensino. Brasília: ME, jun. 2015c. Disponível em:

<http://pne.mec.gov.br/images/pdf/SNE_junho_2015.pdf> Acesso em: 30 set. 2015.

CANELA JÚNIOR, Osvaldo. Controle judicial de políticas públicas. São Paulo: Saraiva, 2011.

CURY, Carlos Roberto Jamil. Sistema nacional de educação: uma reflexão provocativa ao debate. In: BRASIL. Ministério da Educação; CUNHA, Célio da. O Sistema Nacional de Educação: diversos olhares 80 anos após o manifesto. Brasília: MEC, 2014.

FERREIRA, Luiz Antonio Miguel; DIDONET, Vital. Educação infantil: creches período integral e parcial - Férias. 2015. Mimeo.

DELGADO, Adriana Patrício. O impacto das políticas públicas nas práticas escolares sob a ótica da avaliação de aprendizagem. Espaço do Currículo, v. 4, n. 2, p.162-171, set./mar. 2011/ 2012. Disponível em: <http://periodicos.ufpb.br/ojs2/index.php/rec162> Acesso em: 30 set. 2015.

MARTINS, Ângela Maria.; PIMENTA, Cláudia Oliveira; NOVAES, Gláucia Torres Franco. Planos municipais de educação: potencialidades e limites de municípios na elaboração de instrumentos de planejamento. In: SOUZA, Donaldo Bello de; MARTINS, Angela Maria (Org.). Planos de educação no Brasil: planejamento, políticas, práticas. São Paulo: Edições Loyola, 2014.

POR UMA PARTICIPAÇÃO que faça dos Planos de Educação um avanço na garantia de direitos!. Planos de educação. [S.1.]: De olho nos planos, 2015. Disponível em: < http://www.deolhonosplanos.org.br/planos-de-educacao/> Acesso em: 30 set. 2015.

RODRIGUES, Marta Maria Assumpção. Políticas públicas. São Paulo: Publifolha, 2010.

VIEIRA, Lerche Sofia. Planos e políticas educacionais: das concepções às práticas. In: SOUZA, Donaldo Bello de; MARTINS, Angela Maria (Org.). 
Planos de educação no Brasil: planejamento, políticas, práticas. São Paulo: Edições Loyola, 2014. 